\title{
A Study on the Integration of Picture Books into Kindergarten Mathematics Collective Teaching Activities and the Influence on Children's Learning Attitudes
}

\author{
Zhang Xuan \\ School of Preschool Education, Xi’an University, Xi’an, Shaanxi, China, 710065
}

Keywords: picture books; mathematics collective teaching in kindergarten; learning attitude in math

\begin{abstract}
This study, based on the research of the 30 children in the senior grade of kindergarten, conducts the experiment research on integrating the picture books into kindergarten mathematics collective teaching activities, and explores the influence on children's learning attitudes. The result shows that, the children performance of the treatment group in learning mathematics is better than those in control groups.
\end{abstract}

\section{Introduction}

In recent years, there are various picture books springing up, which draw a lot people's attention. Picture books are more and more popular among people due to its vivid language and beautiful, elegant pictures, and are considered to be the best reading material for children. It is always been a concern for the academic community how to promote the children's mathematics ability through multiple ways. The integration of general ideas contains in the Kindergarten Education Guidelines, enlightens the front-line educators to combine the picture books with children mathematics education, and transfer the monotonous mathematics into vivid knowledge. It offers the education activities to children with picture books of mathematical core experience, which stands out the idea of the courses of integration.

The researchers are focusing on picture books into pre-school mathematics education; however, there are few studies in this way in China. Most of the researchers are paying the attention to reflection of the teaching activities by the teachers on front, and some fragmented strategies for specific activities. There are few systematic analysis and argumentation. Based on this background, our research is exploring the differences of the children's attitude in learning mathematics with the integration of picture books or not, through the experiments that study the pictures books into the kindergarten mathematics collective teaching activities.

\section{Research Methods}

\subsection{Testing objects}

It chooses 30 children of the senior grade kindergarten in Xi'an. With the stratified sampling method, the children in large classes are divided into two groups according to gender. Then, it randomly selects half of the children from the two groups to form the experimental group, the other half left are the control group. It is for eliminating the influence of gender differences on the results of the study. The average of the testing object is 5.09, and the standard deviation is 0.49 , as shown in Table 1.

Table 1 Testing table

\begin{tabular}{|c|c|c|c|c|c|}
\hline \multirow{2}{*}{ Group } & \multicolumn{2}{|c|}{ Age } & \multicolumn{2}{|c|}{ Gender } & Total \\
\hline & $\mathrm{M}$ & SD & Male & Female & \\
\hline Treatment group & 5.12 & 0.27 & 7 & 8 & 15 \\
\hline Control group & 5.05 & 0.65 & 7 & 8 & 15 \\
\hline Total & & & 14 & 16 & 30 \\
\hline
\end{tabular}




\subsection{Research tool}

This research employed the Mathematics Learning Attitude Test Scale by Zeng Anru from the beginning to the end, to perform the test to the 30 children of senior grade in a kindergarten separately in Xi'an. With the Likert Scale, there are 5 grades of very much agree, agree, do not know, disagree, and strongly disagree, which are respectively with 5 points, 4 points, 3 points, 2 points, 1 point. The scale has been measured as 0.826 by internal constant coefficient analysis, so that it received a high reliability.

\subsection{Program}

At the beginning and end of the research, it applied the same Mathematics Learning Attitude Test Scale, and tested the treatment and control group separately. The experimenter sat next to the children and performed the test individually. At first, the experimenter raised the question, and then received the children's feedback, at the same time, observed and recorded children's performance.

The experiment dealing of the treatment group about the picture books into the mathematics collective teaching activities. This research screened the mathematical picture books on the market, selecting the 4 core mathematics experience areas containing collections and patterns, number concepts and operations, graphics and space, comparison and measurement, and chose the mathematics picture books suitable for the senior grade children. It extended an 8-week experiment study based on the picture books as the blueprint, and integrated the picture books into the mathematics teaching curriculum once a week.

There is no dealing with the control group. The teaching activity remained regular without the integration of picture books.

\subsection{Statistical disposition}

Analyzing the data with SPSS 17.0 statistical software.

\section{Results}

\subsection{The significant difference}

This research aims at analyzing the children's learning attitude on math with the picture books into the mathematics collective teaching activities or without. It applied the covariance analysis. Among it, the picture books into teaching is independent variable, and the performance of math learning attitude is dependent variable, then the performance before the picture books into the mathematics collective teaching is concomitant variable. It shows from the table 2 with the analysis of covariance, that the post-test performance scores of the learning attitude with picture books into mathematics teaching from the treatment group varies from the control group's $(\mathrm{p}<0.05)$.

Table 2 Covariance analysis summary table of mathematics learning attitudes

\begin{tabular}{cccccc} 
Source & Type III Sum of squares & df & Mean square & F & Sig. \\
\hline Pretest score & 456.387 & 1 & 456.387 & 251.755 & 0.00 \\
Intra-group & 182.082 & 1 & 182.082 & 100.441 & 0.00 \\
error & 48.946 & 27 & 1.813 & & \\
\hline
\end{tabular}

\subsection{Treatment group are better than control group}

From the table 3, treatment group’s learning attitude is better than control group.

Table 3 Average and standard deviation of mathematics learning attitudes

\begin{tabular}{ccccc}
\hline & \multicolumn{2}{c}{ Treatment group } & \multicolumn{2}{c}{ Control group } \\
\hline & Pretest & Post-test & Pretest & Post-test \\
\cline { 2 - 5 } M & 45.27 & 54.47 & 45.33 & 49.6 \\
SD & 3.99 & 4.02 & 4.84 & 4.47 \\
\hline
\end{tabular}

After finishing the experiment that blends the picture books into the senior grade mathematics 
collective teaching activities, it shows that the learning attitude in math of the treatment group is much better than control group.

With picture books into children's mathematics collective teaching, the treatment group's cognitive aspect is much better than control groups. Before the experiment, for most of the children, learning math is dry and dull. Except for the math lessons, there are few things which would apply for math. Math becomes a great pressure on them. With the picture books integrating into math lessons, it renders the children with the pleasure and usefulness of learning math which makes a essential changes on the cognition.

Compared with control group's math teaching integrated without picture books, the math collective teaching with picture books enhances the learning a lot in emotional aspect. Ahead of the experiment, most of the children are afraid of being asked about the math question by teachers. If they are informed that there is no math lesson, they will feel relaxed. However, when the picture books applied to the mathematics collective activities, this have reduced the children's anxiety in math learning a lot and lightened the burden of the math teaching.

In addition, when children are receiving the math teaching lessons with picture books, their performance and attention are more focused which indicates the higher participation of children exploring the lesson and the active atmosphere of the classroom. In contrast, the children from control group are always after teachers step without initiative. Therefore, raising the initiative of children is the real value of the integration of picture books into the collective mathematics teaching.

\section{Discussion}

There is great enhancement of learning attitude with the integration of picture books into the collective mathematics teaching. It will receive more and more popularity among children. Compared with the simple "knowledge"-based teaching mode, the integration of picture books into the collective mathematics teaching, can improve children's knowledge quality and moral quality.

\section{Acknowledgement}

Innovation and Reform of Preschool Children's Mathematical Education Teaching Model in the Background of Integrated Courses of Xi'an University of Arts and Sciences, Project No.: JG2017059

\section{References}

[1] Cai Jiangwei, Subverting the Tradition and Rebuilding Children's Mathematics with Mathematical Books [J]. Primary school teaching, 2009, 32:30

[2] Cao Yingjie, Picture Books Make Mathematics Activities More Interesting [J]. Examination Weekly, 2012, 58: 193

[3] Huang Jin, Preschool Children's Mathematics Education [M]. East China Normal University Press, 2010

[4] Feng Fang, An Analysis of Kindergarten Mathematical Picture Book Teaching [J]. 2013, 12:39-41

[5] Lou Wenyao, Talking about the Application of Picture Books in Kindergarten Mathematics Teaching Activities [J]. Science Popular (Science Education), 2013, 09:91

[6] Zhang Lifen, Combining the Effect of Picture Books and Mathematics Teaching Methods on Children's Mathematical Ability [J]. Journal of Taipei Municipal Education University, 2009, 2

[7] Zhang Lifen, The Influence of Mathematical Teaching Using Picture Books on Children's Mathematics Learning Attitude [J]. Journal of Pingtung Education University, 2011.3 